\title{
A VALORAÇÃO DA PROVA ORAL NO PROCESSO PENAL BRASILEIRO
}

\author{
Lucas Ferreira Furlan \\ Universidade do Oeste Paulista - UNOESTE, Presidente Prudente, SP. E-mail: lucasfurlan94@hotmail.com
}

\section{RESUMO}

O presente trabalho teve como principal objetivo a realização de um levantamento jurisprudencial quanto à análise que tem sido realizada pelos Tribunais quando da valoração da prova oral no âmbito do processo penal pátrio. Inicialmente foram tecidas breves considerações quanto ao sistema de valoração probatória adotado majoritariamente no Brasil - persuasão racional - para na sequência se adentrar objetivamente na avaliação da prova oral pela jurisprudência nacional. Nesta esteira, foram analisados diversos acórdãos do Supremo Tribunal Federal, Superior Tribunal de Justiça e de diversos Tribunais Estaduais, nos quais firmou-se precedentes quanto a valoração da palavra da vítima, depoimento de testemunhas policiais e informantes, bem como das declarações do réu, seja ele colaborador ou não. A coleta de dados foi realizada com embasamento em fontes acessíveis, tais como: documentos impressos, artigos científicos, livros e julgados, sempre ponderando a necessidade coleta de dados de variadas fontes. Os dados foram analisados com emprego do método hipotético-dedutivo, informações coletadas analisadas e confrontadas de forma dialética. Os resultados alcançados com a pesquisa com concretos quanto à contribuição ao debate que permeia o tema, concluindo-se pela necessidade de construção de um balizamento jurisprudencial que permita a valoração da prova de forma a respeitar os princípios da presunção de inocência e da vedação da proteção deficiente.

Palavras-chave: Processo. Testemunha. Vítima. Réu. Valoração.

\section{THE VALUATION OF ORAL EVIDENCE IN THE BRAZILIAN CRIMINAL PROCESS}

\begin{abstract}
The present work had as main objective the accomplishment of a jurisprudential survey regarding the analysis that has been carried out by the Courts when evaluating the oral evidence in the scope of the domestic criminal process. Initially, brief considerations were made regarding the system of evidential valuation adopted mostly in Brazil - rational persuasion - in order to enter objectively in the assessment of oral evidence by national jurisprudence. In this context, several judgments of the Supreme Federal Court, Superior Court of Justice and several State Courts were analyzed, in which precedents were established regarding the valuation of the victim's word, the testimony of police witnesses and informants, as well as the statements of the defendant, whether he is a collaborator or not. Data collection was performed based on accessible sources, such as: printed documents, scientific articles, books and judges, always considering the need for data collection from various sources. The data were analyzed using the hypothetical-deductive method, collected information analyzed and compared in a dialectical way. The results achieved with the research with concrete as to the contribution to the debate that permeates the theme, concluding by the need to build a jurisprudential framework that allows the valuation of the evidence in order to respect the principles of the presumption of innocence and the prohibition of protection deficient.
\end{abstract}

Keywords: Process. Witness. Victim. Defendant. Valuation. 


\section{INTRODUÇÃO}

A produção e valoração probatória constitui um dos principais pontos de debate no âmbito do processo penal, sobretudo, pela sensibilidade dos direitos envolvidos no âmbito da persecução penal. Desta feita, o julgador quando da valoração da produção probatória encartada aos autos no curso da instrução processual, deve valer-se de adequados métodos de valoração e conformação dos elementos de conviç̧ão produzidos, isso com fins de alcançar os escopos atinentes à jurisdição penal.

Destarte, é certo que quando do processamento e julgamento da prática, em tese, de uma infração penal, a produção e valoração de provas orais configuram o principal elemento de cognição fornecido ao julgador para formação de seu convencimento, salvo escassas exceções, consiste estas, nas declarações fornecidas pelo ofendido, depoimento das testemunhas e pelo interrogatório do próprio acusado.

Ora, é certo que no âmbito do processo penal, considerando-se a égide dos princípios constitucionais da presunção de inocência, do contraditório e da ampla defesa, a prolação de um decreto condenatório só mostra-se compatível com a ordem democrática, quando calcado em provas cabais de materialidade e autoria delitiva, prova esta que é ônus do acusador, motivo pelo qual o julgador deve empregar toda a cautela quando da valoração das provas orais, eis que inevitavelmente, estas podem se mostrar viciadas por fatores estranhos ao processo.

Nesta esteira, o presente artigo tem como objetivo a realização de um levantamento doutrinário e jurisprudencial quanto a atual valoração fornecida pelos operadores de direito quando da apreciação das provas orais no âmbito do processo penal, visando o enfrentamento de questões delicadas, como a palavra da vítima no âmbito dos crimes sexuais, o testemunho de agentes policias quando de crimes contra 0 patrimônio e o valor das declarações do réu nos crimes de tóxicos.

\section{METODOLOGIA}

O artigo foi norteado por pesquisas bibliográficas, leituras e fichamentos. A delimitação do tema foi realizada com base na pertinência do assunto, bem como, na finalidade objetivada pelo presente estudo. Os conhecimentos prévios existentes juntamente comas possibilidades de tempo e pesquisa disponíveis delimitaram a profundidade da abordagem realizada.

A coleta de dados foi realizada com embasamento em fontes acessíveis, tais como: documentos impressos, artigos científicos, livros e julgados, sempre ponderando a necessidade coleta de dados de variadas fontes. Os dados foram analisados com emprego do método hipotéticodedutivo, informações coletadas analisadas e confrontadas de forma dialética.

\section{PROBLEMÁTICA: A VALORAÇÃO DAS PROVAS E O LIVRE CONVENCIMENTO MOTIVADO}

O Código de Processo Penal já em sua Exposição de Motivos firmou que todas as provas devem ser consideradas relativas, não havendo provas que usufruam de maior relevo ou prestígio se comparadas com as demais. Desta feita, conclui-se que nenhum elemento probatório pode fazer de forma isolada inquestionável demonstração da culpabilidade do réu.

Destarte, a opção processual brasileira quando da apreciação da matéria probatória foi de encontro com o sistema da prova legal ou tarifada, por meio do qual cada elemento probatório possui um relevo específico, cabendo ao julgador somente avaliar de forma dosimétrica as provas que lhe foram apresentadas e a partir desta análise objetiva, externar sua decisão (GRECO FILHO, 2015).

Não obstante, em que pese à discricionariedade conferida ao julgador quando da apreciação da prova produzida nos autos, teve o Código de Processo Penal a cautela de impedir, via de regra, a mera adoção pelo magistrado do critério da livre conviç̧ão, por meio do qual, pode o juiz externar uma decisão completamente desvinculada da prova dos autos, não estando obrigado sequer a fundamentar os motivos que o levaram a determinada conclusão (MOSSIN, 2010).

Neste ponto, destaca-se que já em sua exposição de motivos, teve o Código de Processo Penal o cuidado de asseverar que o juiz possui a livre interpretação das provas produzidas no curso da investigação e da fase processual, contudo, necessariamente, deveria externar uma decisão que se encontre atrelada aos elementos de convicção produzidos no curso contraditório judicial, tal qual assevera o artigo 155 do referido Diploma Processual.

No âmbito do referido raciocínio, ainda mostra-se necessário destacar que o Código de 
Processo Penal abriu a possibilidade de que o julgador fundamente sua decisão nas provas ainda produzidas no curso da investigação, desde que estas constituam aquelas classificadas como cautelares, não repetíveis e antecipadas, ponderando-se que tais elementos probatórios ainda são submetidos ao contraditório, contudo, apenas após a obtenção dos elementos de informação necessários a apuração dos fatos, ou seja, trata-se de um contraditório diferido (AVENA, 2018).

No mais, ainda é certo que a jurisprudência tem admitido o embasamento de condenações por meio dos elementos de informação colhidos somente no inquérito, deste que estes se mostrem em harmonia com a prova produzida em Juízo, ou seja, o magistrado pode livremente apreciar os elementos de convicção existentes tanto no inquérito, como no processo, podendo alcançar uma conclusão calcada na ponderação conjunta de tais meios de prova (BRASIL, 2019a).

Destarte, deve-se ainda destacar que a doutrina tem advogado a tese de que a vedação da fundamentação exclusiva da decisão judicial com base nos elementos de informação colhidos na investigação deve ser interpretada como um regramento legal instituído em favor do acusado, motivo pelo qual, não existiria óbice que eventual édito absolutório viesse calcado exclusivamente nos elementos de cognição colhidos no procedimento inquisitivo (MACHADO, 2014).

Desta forma, excetuado os casos em que a legislação exigiu somente a existência de determinados meios de prova para comprovação de certas situações, o processo penal pátrio adotou quando da valoração dos meios de prova o sistema do livre convencimento motivado do juiz ou da persuasão racional, permitindo ao julgador a formação de seu convencimento livremente, por meio da irrestrita interpretação dos meios de prova produzidos nos autos, sem qualquer tipo de vinculação legal (BRASIL, 2012).

No mais, deve-se ainda destacar que a necessidade de fundamentação das decisões constitui hoje verdadeiro postulado constitucional, sendo que jurisprudência do Supremo Tribunal Federal é remansosa ao afirmar que tal realidade constitui não somente um fator de limitação ao exercício do poder estatal, como também, instrumento essencial de respeito e proteção às liberdades públicas (BRASIL, 1992).
Desta feita, a recepção do livre convencimento motivado como sistema de valoração probatória adotado pelo Código de Processo Penal decorre não somente da busca por um procedimento que confira ao julgador condições de perquirir a verdade real no curso do processo, mas também, do mandamento constitucional que obriga a fundamentação de todas as decisões judiciais, necessidade esta inerente ao Estado Democrático de Direito.

Destarte, no decorrer do próximo tópico serão tecidas considerações quanto à interpretação e valoração que a doutrina e a jurisprudência pátria têm conferido aos meios de prova oral no âmbito do processo penal, considerando-se a égide da persuasão racional do julgador quando da apreciação da matéria de prova.

\section{RESULTADO E DISCUSSÃO: DO VALOR DA PROVA ORAL E DOS CRITÉRIOS DE AVALIAÇÃO.}

Como já ponderado, ante a não existência de critérios legais para valoração da prova oral, bem como, destacando-se a positivação no sentido de que o magistrado possui livre discricionariedade para apreciação das provas encartadas no curso da investigação e instrução, a doutrina e jurisprudência passaram a estabelecer critérios de orientação ao julgador, em que pese à existência de divergências que serão exploradas no curso deste tópico.

Ressalta-se que tal estudo se mostra indispensável devido à notória influência da prova oral no âmbito da elucidação dos casos submetidos à apreciação da jurisdição penal. Ora, mesmo com o avanço dos meios tecnológicos e a consequente existência de diversos métodos contemporâneos de produção probatória, o processo penal ainda se encontra majoritariamente dependendo da produção da prova testemunhal para a instrução dos processos penais.

Destarte, quanto à apreciação da prova testemunhal, Francesco Carnelutti (1957, p.33), já advertia que:

Os juristas, friamente, classificam a testemunha, junto com o documento, na categoria das provas. Aliás é uma certa categoria das provas. Esta frieza deles é necessária como a do anatomista que secciona o cadáver; mas ai de nós se esquecermos 
que, enquanto 0 documento é uma coisa, a testemunha é um homem; um homem com o seu corpo e com a sua alma, com seus interesses e com as suas tentações, com as suas lembranças e com os seus esquecimentos, com a sua ignorância e com a sua cultura, com a sua coragem e com o seu medo. Um homem que o processo coloca em uma posição incômoda e perigosa, submetido a uma espécie de requisição para utilidade pública, afastado de seus afazeres e sua paz, pesquisado, espremido, inquirido, suspeitado. Não conheço um aspecto da técnica penal mais preocupante do que aquele que resguarda o exame, aliás, em geral, o tratamento da testemunha.

Desta feita, é certo que pela sua simples condição, deve a prova testemunhal ser apreciada com redobrada cautela por parte do magistrado, visto que inevitavelmente, trata-se de um meio probatório que pode, em muitos casos, se mostrar viciado por fatores estranhos ao processo, os quais nem sempre, irão possibilitar a sua formal impugnação pelos meios prescritos na legislação de regência. Neste contexto, irá se buscar destacar os principais critérios de valoração empregados pela jurisprudência pátria, quando da valoração da prova oral.

Inicialmente, desataque-se que no âmbito da atual compreensão do sistema probatório processual percebe-se a inequívoca atribuição de relevante valor a palavra prestada pela vítima quando de seu depoimento, isso em que pese parte da doutrina advertir para a necessidade de conferência de um valor relativo a palavra prestada pelo ofendido já que este invariavelmente apresenta interesses particulares frente ao deslinde do processo penal (MOSSIN, 2010).

Contudo, não obstante tal advertência tem prevalecido na jurisprudência pátria $\mathrm{o}$ entendimento de que o depoimento prestado pelo ofendido, quando coerente e isento de máfé, tem fundamental importância, eis que seu único interesse seria delimitar a autoria da infração e suas demais variantes, sem o desejo de acusar um eventual inocente (SANTA CATARINA, 2008).

Desta feita, tornou-se comum a existência de sentenças penais condenatórias calcadas substancialmente nas declarações prestadas pelo ofendido, sobretudo, quando da prática de crimes que costumeiramente são praticados distantes da presença de testemunhas, como, por exemplo, os perpetrados no âmbito doméstico (BRASIL, 2019b).

Tal realidade é igualmente verificada quando da apuração de crimes sexuais (BRASIL, 2019c), nestes ainda com maior vigor, eis que nos delitos de tal natureza, mostra-se mais comum à inexistência de outros meios de prova que não a palavra da vítima, visto que quase sempre são perpetrados longe de testemunhas e em muitos casos, a violência sexual empregada pelo agente não deixa vestígios.

Não obstante, mesmo neste gênero de delitos, não se olvidando da dificuldade probatória que muitas vezes norteia o processo penal, é certo que a valoração probatória sempre deverá ser procedida com cautela pelo magistrado, não podendo a palavra da vítima necessariamente se sobrepor a do réu somente por sua condição, sendo certo que diversos julgados advertem que tal realidade somente será alcançada quando as declarações da vítima encontrem amparo em outros meios de prova.

Neste sentido, destaca-se pertinente precedente do Tribunal de Justiça do Estado de Minas Gerais, note-se:

As declarações da vítima, isoladas, não podem ensejar um decreto condenatório, seja por qual crime for, clandestino ou não. Tal assertiva tem por fundamento um princípio básico a ser observado em todo processo, cuja finalidade seja a composição de uma lide: a igualdade de tratamento a ser dispensado às partes, não podendo a versão de uma ter um peso superior à da outra, exceto quando esta valoração se mostra 
amparada em outros elementos de convicção (MINAS GERAIS, 2016).

No âmbito dos crimes contra o patrimônio a orientação tem prevalecido, contudo, quando da apuração destes crimes é comum ser ainda mais latente a exigência de que a palavra da vítima, para gozar do prestígio que Ihe é inerente, venha corroborada pela existência de outros meios de prova encartados aos autos (BRASIL, 2017).

Não obstante, é certo que dada à sensibilidade dos direitos que se encontram passíveis de mitigação no âmbito do processo penal, mostra-se como necessária a valoração cautelosa por parte do julgador de todos os elementos de provas constantes aos autos, em especial a palavra do ofendido, visto que a própria tensão inerente à condição de vítima, pode levar a eventual viciamento das declarações a serem externadas.

Frente a esta realidade, a melhor linha jurisprudencial caminha no sentido de que necessariamente, para arrimar uma sentença penal condenatória, a palavra da vítima deve se mostrar clara, coesa, livre de contradições, bem como, de indícios que possam indicar animosidade pretérita com o acusado ou mesmo intenção de lhe prejudicar, sem prejuízo ainda de outros elementos de prova que lhe confiram respaldo (RIO GRANDE DO SUL, 2019).

Destarte, no âmbito da busca de meios para se verificar a credibilidade das declarações prestadas pela vítima, à jurisprudência pátria tem atribuído relevante valor as declarações previamente prestadas por esta ainda no âmbito do Inquérito Policial, isso como forma de verificar-se a verossimilhança com as informações posteriormente prestadas por ocasião de seu depoimento judicial.

Nesta linha, são diversos os julgados que fazem menção a informações prestadas pelo ofendido quando de seu depoimento inquisitivo, tanto para lhe conferir idoneidade, quando para levantar questões quanto a sua credibilidade. Neste sentido, destacam-se dois acórdãos proferidos pelo Tribunal de Justiça do Distrito Federal e dos Territórios, note-se:

Nos crimes praticados no
âmbito familiar e
doméstico, a palavra da
vítima reveste-se de
especial credibilidade,
sobretudo quando narra

os fatos de forma coerente e harmônica nas oportunidades em que é ouvida e suas declarações confirmam os depoimentos prestados durante a fase do inquérito (DISTRITO FEDERAL, 2019).

A palavra da vítima sempre foi reputada especialmente importante na apuração de crimes, mas desde que se mostre lógica, consistente e corroborada por um mínimo de evidências outras. As contradições existentes nos depoimentos prestados no inquérito policial e em Juízo não autorizam a derrogação da presunção de inocência que milita em favor do réu (DISTRITO FEDERAL, 2015).

Assim, frente à valoração probatória conferida a palavrava da vítima, sua oitiva inquisitiva passou a ter dupla finalidade, para além de permitir a rápida colheita de informações quanto à autoria dos fatos, sua dinâmica, motivação e demais circunstâncias relevantes (MARCÃO, 2018), ainda mostra-se salutar a posterior verificação de credibilidade das declarações, ante a análise sistémica das afirmações por ocasião do Inquérito Policial e posteriormente em Juízo.

Não obstante, com a aprovação da Lei n. 13.964/19 (Pacote Anticrime) e a consequente instituição do Juiz das Garantias, tal análise jurisprudencial necessariamente terá de ser conformada frente à nova realidade legislativa imposta, isso ante a redação do artigo 3--C, § 3으, do Código de Processo Penal, a qual positiva que os autos de Inquérito Policial permaneceram acautelados junto a secretaria do Juízo das Garantias, disponíveis ao Ministério Público e defesa, mas não serão apensados aos autos enviados ao Juízo da Instrução e Julgamento.

Ora, tal realidade retiraria, em princípio, a possiblidade de que o magistrado da instrução processual realizasse a verificação e convergência entre as declarações prestadas pelo ofendido e demais testemunhas na fase de Inquérito Policial 
e posteriormente em Juízo, fulminando assim, um importante e usual meio de verificação da credibilidade da prova oral produzida em Juízo.

É certo que tal realidade ainda deverá ter sua análise aprofundada pela doutrina e jurisprudência pátria, já havendo, contudo, respeitável corrente doutrinária firmando que tal determinação vai ao encontro do sistema acusatório, eis que os elementos de informação produzidos no âmbito inquisitivo deveriam interessar apenas quando da análise da justa causa da ação penal e não na apreciação de seu mérito (NUCCl, 2020).

Não obstante, é certo que neste ponto, a análise dos elementos de informação constantes do Inquérito Policial não serviria ao magistrado para fins de verificar a densidade probatória quanto a materialidade e autoria delitiva, mas sim, como forma de verificação de idoneidade da declarações que foram prestadas em Juízo pelas vítimas e testemunhas, realidade esta que inclusive se mostra salutar a busca da verdade real.

Frente a esta realidade, não haveria que se obstar por exemplo que o defensor do réu ao perceber a existência de graves incongruências entre as declarações prestadas pela vítima na fase inquisitiva e posteriormente em Juízo, procedesse com a juntada nos autos de ação penal do depoimento previamente prestado por esta na fase de investigação, isso com fins de explicitar ao julgador da causa tal realidade.

Tal compreensão vai no sentido de que a vedação constante no artigo 3 ㅇ-C, § 3 으, do Código de Processo Penal é direcionada ao Juiz das Garantias e não as partes do processo penal, sobretudo, pelo próprio dispositivo legal determinar que os autos de Inquérito Policial irão permanecer à disposição da acusação e defesa, ponderando-se ainda que o artigo 156 do Código de Processo Penal continua a permitir que 0 magistrado use sistemicamente os elementos de informação da fase inquisitiva para formar sua convicção (ALBECHE, 2020).

No mais, para além das declarações prestadas pela vítima, o depoimento das testemunhas inquiridas em Juízo se mostra igualmente fundamental para elucidação da maioria dos crimes, sobretudo na apuração daqueles que não possuem vítima determinada, como os crimes de tóxicos por exemplo. Neste ponto, surge com grande relevância o debate relacionado ao valor que deve ser conferido ao depoimento prestado pela autoridade policial muitas vezes responsável pelo atendimento da ocorrência ou mesmo investigação dos fatos.

Frente a esta realidade, existe entendimento do sentido que o depoimento policial isolado não poderia vir a embasar eventual decreto condenatório, eis que a função da Autoridade Policial seria de trazer elementos para formação do convencimento do magistrado e não de testemunhar os fatos, devendo inclusive suas declarações ser apreciadas com reservas. Neste sentido, destaca-se pertinente precedente do Tribunal de Justiça do Estado de Minas Gerais, note-se:

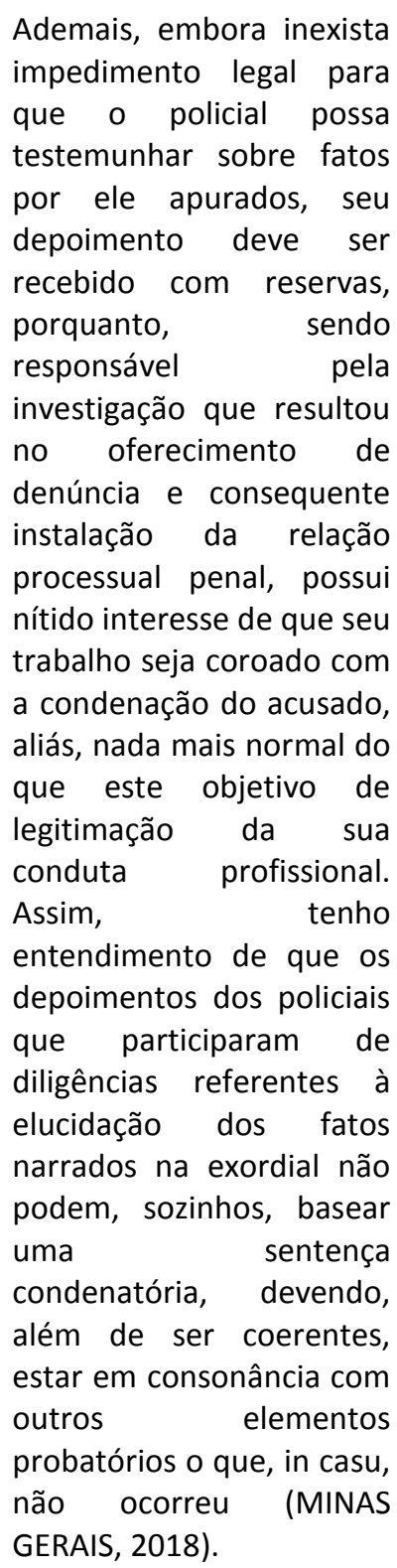

Contudo, não obstante tal precedente, o entendimento prevalecente na jurisprudência pátria vai no sentido de que o depoimento dos servidores policias deve ser analisado sem qualquer tipo de reversas, sobretudo, quando prestado em Juízo, sob o compromisso legal de 
dizer a verdade e com o crivo do contraditório e da ampla defesa. Entende-se que o testemunho do policial deve ser valorado como o de qualquer outra testemunha, só podendo ser desacreditado quando demonstrado interesse particular na causa ou má-fé (BRASIL, 1996).

Nesta esteira, no âmbito dos procedimentos relacionados a prática, em tese, dos crimes de tóxicos, mostra-se como muito comum a existência de julgados nos quais se firma o entendimento de que o testemunho do policial deve prevalecer em face das declarações do agente, salvo a existência de provas em sentido contrário (PARANÁ, 2013). Tal entendimento se mostra importante à compreensão da repressão penal a tais condutas, eis que notoriamente, figura o policial, costumeiramente, como a principal testemunha deste tipo de crime.

Ressalta-se inclusive que na doutrina é possível perceber a existência de posicionamentos no sentido de que se deve ainda conferir maior relevo probatório ao depoimento prestado pela autoridade policial, quando comparado com as demais testemunhas, isso em decorrência da função pública exercida. Nesta linha, pertinente destacar-se às lições de Framarino de Malatesta, ao asseverar que:

Não é só por estas
considerações que (...)
tem um maior valor
quando prestada por
funcionário público
competente que quando
por uma testemunha
ordinária, mas também
pela maior fé que inspira
subjetivamente aquele
funcionário público como
testemunha de segundo
grau. Supõe-se que
desempenhando um dever
de ofício, um funcionário
público quererá sempre
prestar mais atenção que
um particular, munido
somente do estímulo da
curiosidade; portanto,
menor facilidade de
engano na testemunha
oficial. Sabe-se que, além
do senso moral que
ordena a verdade de
todos, existe no espírito da
testemunha oficial o
sentimento de um dever

particular e uma particular responsabilidade, que se opõem à mentira; por isso menor facilidade de vontade de enganar no funcionário público (MALATESTA, 1986).

Destarte, na linha deste entendimento, torna-se cada vez mais comum a existência de precedentes que conferem a tais declarações relevo probatório superior às demais provas orais encartadas aos autos, isso ante a presunção de veracidade que permeiam os atos funcionais praticados por funcionários públicos no exercício de suas funções (SÃO PAULO, 2020).

Assim, na esteira deste entendimento, existindo divergências entre as declarações prestadas pelos policiais militares e outra testemunha qualquer, deve prevalecer à versão apresentada pelos policiais, salvo, quando para além de prestar informações distintas da Autoridade Policial, a outra testemunha demonstre a existência de interesse particular ou mesmo má-fé por parte dos policiais.

Ressalta-se ainda que a jurisprudência tem destacado que a existência de pequenas divergências entre as declarações prestadas pelos policiais devem ser interpretadas como naturais, isso em razão muitas vezes do decurso do tempo e inevitavelmente de quantidade de ocorrências atendidas diariamente, motivo pelo qual, desde que relacionadas a aspectos secundários, tais incongruências não se prestam a macular a prova (SÃO PAULO, 2018).

Outro ponto que deve ser destacado diz respeito à valoração dos depoimentos dos informantes, ou seja, daqueles que depõem em Juízo sem o compromisso legal de dizer a verdade, na forma preceituada pelo Código de Processo Penal. Nesta esteira, deve-se ponderar que o Código de Processo Penal possui regramento próprio quanto as pessoas que não devem prestar o compromisso legal de dizer a verdade, sendo que a doutrina e a jurisprudência tem firmado que se preocupou o legislador em restringir ao máximo este rol, dada a busca pela verdade real.

Neste sentido, destaca-se trecho da ementa de importante precedente proferido pelo E. Superior Tribunal de Justiça, note-se:

Conforme leciona a doutrina, o rol do art. 206 do CPP "é taxativo e uma das principais razões para 
isso é o princípio da verdade real. No processo penal, reduz-se ao mínimo possível a lista de pessoas que não prestam o compromisso de dizer a verdade. Além dos parentes do acusado, os menores de 14 anos e os enfermos mentais. Ninguém mais se isenta desse dever". (NUCCl, Guilherme de Souza. Código de Processo Penal comentado. 18. ed. Rio de Janeiro: Forense, 2019. p. 576). Nesse contexto, conforme consignado pelo Ministro Nefi Cordeiro, no AREsp n. 1.021.166/DF, julgado em 1이일, "não se encaixa no rol das testemunhas

descompromissadas, consoante art. $206 \mathrm{c} / \mathrm{c}$ art. 208, ambos do CPP, colateral em terceiro grau" (BRASIL, 2019d).

Com base nesta realidade, a jurisprudência ainda tem buscado conformar os meios que deveram ser utilizados pelo magistrado quando da valoração das declarações prestadas pelos informantes em Juízo. Neste âmbito, a linha jurisprudencial tem apontado para o norte de que o depoimento do informante não pode ser desconsiderado por sua simples condição, devendo o julgador atribuir a este o relevo probatório que entender pertinente, isso frente ao conjunto do acervo probatório (DISTRITO FEDERAL, 2014b).

Tal entendimento sem dúvidas é uma decorrência lógica do princípio da persuasão racional do julgador, contudo, é certo que tratando-se de depoimento prestado por pessoa, na maioria dos casos, presumidamente interessada no deslinde da causa, suas declarações devem ser apreciadas com redobrada cautela, sempre em análise de conformidade com os demais elementos de prova constantes dos autos (DISTRITO FEDERAL, 2014a).

Por fim, deve-se necessariamente serem tecidas razões quanto ao valor probatório que deve ser conferido a palavra do acusado no âmbito da instrução processual. Neste ponto, é certo que a natureza jurídica do interrogatório do acusado mostra-se como ponto debatido no âmbito da doutrina, prevalecendo o entendimento de que este constitui inequívoco ato de defesa do réu diante do magistrado que posteriormente irá julgá-lo.

Contudo, tal natureza não retira a força probatória das declarações prestadas pelo réu, devendo julgador aquilatar a força probante destas quando da análise do acervo probatório constante dos autos. Neste ponto, pertinentes às declarações de Antônio Alberto Machado (2014, p. 489), ao asseverar que:

Apesar da celeuma entre os que o consideram uma coisa ou outra, parece óbvio que se trata de ato híbrido, ou seja, ao mesmo tempo em que é um dos elementos mais importantes do conjunto probatório, portanto, um meio de prova, é também um ato essencial à defesa do réu. Hélio Tornaghi, depois de lembrar que essa discussão é uma questão de política processual, parece renderse à natureza híbrida do interrogatório,

sustentando que ele é instrumento de prova, "quando a lei o considera fato probante", ponderando, no entanto, que isso "não significa que o réu não possa valer-se dele para se defender".

Destarte, frente a tal realidade, as declarações do acusado se mostram como capazes de auxiliar na elucidação dos fatos, sobretudo, quando convergentes e harmônicas com os demais elementos de prova que tenham sido encartados aos autos. Nesta esteira, pondera-se que a jurisprudência pátria tem reiteradamente conferido profundo descrédito as declarações isoladas do réu, interpretando que estas constituiriam mero exercício de sua autodefesa (DISTRITO FEDERAL, 2018).

No âmbito de processos com imputações de coautoria, tem a jurisprudência dado importante destaque para confissão do réu que assumindo sua integral participação delitiva, delata a culpa do coautor que visa furtar-se de 
sua responsabilização, isso, desde que as declarações do delator se mostrem coesas e harmônicas com outros elementos de convicção que tenham sido encartados aos autos (PARANÁ, 2019).

Ressalta-se que tal realidade não é aplicada por ocasião dos processos em que réus tenham realizado acordo de colaboração premiada, eis que por força da própria Lei $n$. $12.850 / 13$, deve o magistrado conferir escassa força probatória à palavra do réu colaborador, o qual, inequivocamente, possui notório interesse no deslinde da causa, com o consequente reconhecimento de eventual responsabilidade dos réus delatados.

Destarte, a Lei 12.850/13 trazia inicialmente em seu artigo $4^{\circ}, \S 16$, a proibição de que sentenças condenatórias fossem proferidas com base exclusiva nas declarações do agente colaborador, sendo que já na época desta redação legal, o Supremo Tribunal Federal, em que pese pretéritos precedentes em sentido contrário, decidiu que a palavra do delator, isoladamente, sequer poderia ser usada como indício apto a conferir justa causa ao recebimento de denúncia em desfavor dos delatados (BRASIL, 2018).

Não obstante, a Lei n. 13.964/19 (Pacote Anticrime), deu nova redação ao artigo $4^{\circ}, \S 16$, da Lei 12.850/13, sendo que atualmente a legislação dispõe expressamente que a palavra do réu colaborador não pode embasar isoladamente a decretação de medidas cautelares, sejam elas reais ou pessoais; o recebimento de denúncia ou queixa-crime e a sentença penal condenatória. Neste ponto, avançou bem a legislação ao proibir expressamente que eventuais mitigações a direitos fundamentais venham ser embasadas em meras declarações de agente inequivocamente interessado no resultado do processo.

\section{CONSIDERAÇÕES FINAIS}

$O$ processo penal brasileiro encontra-se em uma fase de indiscutível mutação, tendo por base uma positivação de índole inquisitiva, teve o processo penal pátrio que se adequar nas últimas décadas com uma Constituição de cerne democrático, a qual fez uma inequívoca opção pelo sistema acusatório.

Nesta linha, diversas alterações legislativas e interpretações jurisprudências buscaram amenizar a carga inquisitiva da legislação processual, permitindo uma adequada convivência desta com o regime democrático. Tal realidade inclusive fora verificada quando do sistema probatório, permitindo que o processo penal efetivamente funcione não somente como um meio de aplicação da lei penal, mas também, como garantidor das liberdades individuais e demais preceitos constitucionais.

A importância de trabalhos como este vai justamente ao encontro da necessidade do estabelecimento de adequados critérios jurisprudências para valoração da prova, sobretudo, da prova oral. Ora, não se olvida da necessidade de conferência de ampla liberdade ao magistrado quando da valoração da prova dos autos, contudo, é imprescindível que tal liberdade seja exercida frente a critérios básicos previamente estabelecidos, com fins de se garantir a segurança jurídica e um julgamento isonômico a todos que venham a ser submetidos ao crivo da jurisdição penal.

A produção doutrinária cada vez mais caminha para o abandono da tese da busca da verdade real e a aceitação da realidade posta de que mesmo no processo penal se estará diante de uma verdade processual, isso frente à impossibilidade dos elementos de prova reproduzir em absoluta exatidão os fatos em apreciação, tal qual exatamente se deram. Destarte, indispensável à construção de um balizamento jurisprudencial que permita ao julgador valorar a prova dos autos, de forma a respeitar a presunção de inocência e a vedação da proteção deficiente.

\section{REFERÊNCIAS}

AVENA, Norberto. Processo Penal. 11. ed. Rio de Janeiro: Forense, São Paulo: MÉTODO, 2018.

ALBECHE, Thiago Solon Gonçalves. O inquérito policial foi excluído do processo judicial? Meu Jurídico, 2 jan. 2020. Disponível em: https://meusitejuridico.editorajuspodivm.com.br /2020/01/02/o-inquerito-policial-foi-excluidoprocesso-judicial/. Acesso em: 15 de jul. 2020.

BRASIL. Superior Tribunal de Justiça. AgRg no AgRg no AREsp 1290265/CE. Agravante: B C C C. Agravado: MINISTÉRIO PÚBLICO DO ESTADO DO CEARÁ. Relator: Ministra LAURITA VAZ. SEXTA TURMA. Brasília, DF, 28 de maio de 2019. Disponível em: https://scon.stj.jus.br/sCON/jurisprudencia/toc.js p? processo $=1290265 \&$ tipo_visualizacao $=$ RESUM 
$O \& b=A C O R \&$ thesaurus=JURIDICO\& $p=$ true.

Acesso em: 15 Jun. 2020b.

BRASIL. Presidência da República. Lei Federal n. 13.964/19, de 24 de dezembro de 2019. Aperfeiçoa a legislação penal e processual penal. Diário Oficial da União. Brasília, 24 dez. 2019e.

BRASIL. Superior Tribunal de Justiça. AgRg no AREsp 1480040/SP. Agravante: Maycon Mendes Dias. Agravado: Ministério Público do Estado de São Paulo. Relator: Ministro NEFI CORDEIRO. Sexta Turma. Brasília, DF, 17 de março de 2019. Disponível

em: https://ww2.stj.jus.br/processo/revista/documen to/mediado/?componente=ATC\&sequencial $=101$ $195138 \&$ num_registro $=201901042160 \&$ data $=20$ 191024\&tipo=5\&formato=PDF. Acesso em: 15 Jun. 2020a.

BRASIL. Superior Tribunal de Justiça. AgRg no AREsp 865.331/MG. Agravante: Nelson Michel. Agravado: Ministério Público do Estado de Minas Gerais. Relator: Ministro RIBEIRO DANTAS. Quinta Turma. Brasília, DF, 09 de março de 2017. Disponível em: https://ww2.stj.jus.br/processo/revista/documen to/mediado/?componente=ATC\&sequencial $=702$ 96338\&num_registro $=201600605787 \&$ data $=201$ 70317\&tipo $=5 \&$ formato $=P D F$. Jun. 2020. Acesso em: 15 Jun. 2020.

BRASIL. Superior Tribunal de Justiça. AgRg no RECURSO EM HABEAS CORPUS № 108.823 - SP. Agravante: Gisele de Oliveira. Agravado: Ministério Público Federal. Relator: Ministro REYNALDO SOARES DA FONSECA. Quinta Turma. Brasília, DF, 15 de agosto de 2019. Disponível em: https://ww2.stj.jus.br/processo/revista/documen to/mediado/?componente=ATC\&sequencial $=995$ 92098\&num_registro $=201900548307 \&$ data $=201$ 90830\&tipo $=5 \&$ formato $=P D F$. Acesso em: 15 Jun. 2020d.

BRASIL. Superior Tribunal de Justiça. RHC 115.554/RS. Recorrente: J C DE C. Recorrido: MINISTÉRIO PÚBLICO DO ESTADO DO RIO GRANDE DO SUL. Relator: Ministro LEOPOLDO DE ARRUDA RAPOSO (DESEMBARGADOR CONVOCADO DO TJ/PE). QUINTA TURMA. Brasília, DF, 01 de outubro de 2019. Disponível em:

https://scon.stj.jus.br/SCON/jurisprudencia/doc.j sp . Acesso em: 15 Jun. 2020c.
BRASIL. Supremo Tribunal Federal. HC 69.013/PI. Paciente: Maria de Fátima Pereira da Silva e outros. Coator: Tribunal de Justiça do Estado do Piauí. Relator: Ministro Celso de Mello. Brasília, DF, 24 de março de 1992. DJ 01-07-1992 PP10556 EMENT VOL-01668-02 PP-00160. Disponível em: https://jurisprudencia.stf.jus.br/pages/search/sju r110511/false . Acesso em: 15 Jun. 2020.

BRASIL. Supremo Tribunal Federal. HC 73.518/SP. Paciente: Moises de Oliveira Galvão. Coator: Tribunal de Alçada Criminal do Estado de São Paulo. Relator: Ministro Celso de Mello. Brasília, DF, 10 de outubro de 1996. DJ 18-10-1996 PP39846 EMENT VOL-01846-02 PP-00293. Disponível em: https://jurisprudencia.stf.jus.br/pages/search/sju r118694/false. Acesso em: 15 Jun. 2020.

BRASIL. Supremo Tribunal Federal. Inq 4005. Autor: Ministério Público Federal. Investigado: Fernando Bezerra de Souza Coelho, Aldo Guedes Alvaro e Joao Caros Lyra Pessoa de Mello Filho. Relator: Ministro EDSON FACHIN. Brasília, DF, 11 de dezembro de 2018. ACÓRDÃO ELETRÔNICO DJe-105 DIVULG 20-05-2019 PUBLIC 21-05-2019. Disponível em: https://jurisprudencia.stf.jus.br/pages/search/sju r404250/false. Acesso em: 15 Jun. 2020.

BRASIL. Supremo Tribunal Federal. RHC 103.736/MS. Recte: Defensoria Pública da União. Recdo: Ministério Público Federal. Relator: Ministro Rosa Weber. Brasília, DF, 26 de junho de 2012. ACÓRDÃO ELETRÔNICO DJe-160 DIVULG 14-08-2012 PUBLIC 15-08-2012. Disponível em: https://jurisprudencia.stf.jus.br/pages/search/sju r212827/false . Acesso em: 15 Jun. 2020.

CARNELUTTI, Francesco. AS MISÉRIAS DO PROCESSO PENAL. São Paulo: Editora Pilares, 1957.

DISTRITO FEDERAL (Estado). Tribunal de Justiça do Distrito Federal e dos Territórios. Acórdão n.838882, 20130110141003APC. Apelante: EXCLUSIVA AMINISTRACAO E PREVENCAO DE SAUDE. Apelado: CENTRO CLINICO CDC LTDA. Relator: NÍDIA CORRÊA LIMA. 3a TURMA CÍVEL. Brasília, DF, 03 de dezembro de 2014. Disponível em: 
file://C:/Users/Usesr/AppData/Local/Temp/838 882.pdf . Acesso em: 15 Jun. 2020b.

DISTRITO FEDERAL (Estado). Tribunal de Justiça do Distrito Federal e dos Territórios. Acórdão 1114153, 20170110115816APR. Apelante: EVERTON RAFAEL DA SILVA E OUTROS. Apelado: MINISTÉRIO PÚBLICO DO DISTRITOFEDERAL E TERRITÓRIOS. Relator: SILVANIO BARBOSA DOS SANTOS. 2a TURMA CRIMINAL. Brasília, DF, 28 de agosto de 2018. Disponível em: file:///C:/Users/Usesr/AppData/Local/Temp/111 4153.pdf. Acesso em: 15 Jun. 2020.

DISTRITO FEDERAL. (Estado). Tribunal de Justiça do Distrito Federal e dos Territórios. Acórdão 1209419, 20170110158627APR. Apelante: Daniel dos Santos Bispo. Apelado: Ministério Público do Distrito Federal e dos Territórios. Relator: NILSONI DE FREITAS CUSTODIO. 3a TURMA CRIMINAL. Brasília, DF, 17 de outubro de 2019. Disponível

em: file:///C:/Users/Usesr/AppData/Local/Temp/120 9419.pdf. Acesso em: 15 Jun. 2020.

DISTRITO FEDERAL. (Estado). Tribunal de Justiça do Distrito Federal e dos Territórios. Acórdão 883304, 20120510122343APR. Apelante: DARIEL SOARES FERREIRA. Apelado: Ministério Público do Distrito Federal e dos Territórios. Relator: GEORGE LOPES. 1a TURMA CRIMINAL. Brasília, DF, 16 de julho de 2015. Disponível em: file:///C:/Users/Usesr/AppData/Local/Temp/883 304.pdf. Acesso em: 15 Jun. 2020.

DISTRITO FEDERAL. (Estado). Tribunal de Justiça do Distrito Federal e dos Territórios. Acórdão $\mathbf{n}$. 804585, 20120710293886APR. Apelante: GILLIARD DE SANTANA SPINDOLA. Apelado: MINISTÉRIO PÚBLICO DO DISTRITO FEDERAL E TERRITÓRIOS. Relator: SOUZA E AVILA. 2a Turma Criminal. Brasília, DF, 17 de julho de 2014. Disponível em: https://pesquisajuris.tjdft.jus.br/IndexadorAcord aos-web/sistj. Acesso em: 15 Jun. 2020a.

MINAS GERAIS (Estado). Tribunal de Justiça do Estado de Minas Gerais. Apelação Criminal 1.0024.08.175225-5/001. Apelante: LACIMAR FERREIRA DE SOUZA. Apelado: MINISTÉRIO PÚBLICO DO ESTADO DE MINAS GERAIS. Relator: Alexandre Victor de Carvalho. 5a CÂMARA CRIMINAL. Belo Horizonte, MG, 30 de outubro de 2018. Disponível em: https://www5.tjmg.jus.br/jurisprudencia/pesquis aNumeroCNJEspelhoAcordao.do? numeroRegistro $=1 \&$ total Linhas $=1 \&$ linhasPorPagina $=10$ \& numero Unico $=1.0024 .08 .175225$

5\%2F001\&pesquisaNumeroCNJ=Pesquisar Acesso em: 15 Jun. 2020.

MINAS GERAIS (Estado). Tribunal de Justiça do Estado de Minas Gerais. Apelação Criminal 1.0680.15.000707-7/001. Apelante: MINISTÉRIO PÚBLICO DO ESTADO DE MINAS GERAIS. Apelado: DARLIM SOARES BANDEIRA. Relator: Alexandre Victor de Carvalho. 5a CÂMARA CRIMINAL. Belo Horizonte, MG, 18 de agosto de 2016. Disponível em:

https://www5.tjmg.jus.br/jurisprudencia/pesquis aNumeroCNJEspelhoAcordao.do? numeroRegistro $=1 \&$ total Linhas $=1 \&$ linhasPorPagina $=10$ \& numero Unico $=1.0680 .15$.000707-

7\%2F001\&pesquisaNumeroCNJ=Pesquisar.

Acesso em: 15 Jun. 2020.

SANTA CATARINA (Estado). Tribunal de Justiça de Santa Catarina. Jurisprudência Catarinense. Apelação Criminal n. 2008.013014-9. Apelante: Alencar Moss Floriano e outros. Apelado: Ministério Público do Estado de Santa Catarina. Relator: Solon d'Eça Neves. Primeira Câmara Criminal. Florianópolis, SC, 13 de maio de 2008. Disponível em: http://busca.tjsc.jus.br/jurisprudencia/\#resultado _ancora. Acesso em: 15 Jun. 2020.

SÃO PAULO (Estado). Tribunal de Justiça do Estado de São Paulo. Apelação Criminal 150926705.2019.8.26.0050. Apelante: Hassan Amado Dalle. Apelado: Ministério Público do Estado de São Paulo. Relator: Lauro Mens de Mello. 6a Câmara de Direito Criminal São Paulo, SP, 29 de maio de 2020. Disponível em: https://esaj.tjsp.jus.br/cjsg/getArquivo.do?cdAco $\mathrm{rdao}=13596293 \& \mathrm{cdForo}=0$. Acesso em: 15 Jun. 2020.

SÃO PAULO (Estado). Tribunal de Justiça do Estado de São Paulo. Apelação Criminal 001218628.2015.8.26.0229. Apelante: Marco Aurelio da Silva. Apelado: Ministério Público do Estado de São Paulo. Relator: Cesar Augusto Andrade de Castro. 8a Câmara de Direito Criminal. São Paulo, SP, 01 de março de 2018. Disponível em: https://esaj.tjsp.jus.br/cjsg/getArquivo.do?cdAco rdao $=11227826 \&$ cdForo $=0$. Acesso em: 15 Jun. 2020. 
PARANÁ (Estado). Tribunal de Justiça do Estado do Paraná. AC - 989677-9. Apelante: Edigar Lopes e Luiz Fernando Geremias. Apelado: Ministério Público do Estado do Paraná. Relator: Desembargador Eduardo Fagundes - 5a C. Criminal. Curitiba, PR, 21 de março de 2013. Disponível em: file://C:/Users/Usesr/AppData/Local/Temp/acor dao-989677900.pdf . Acesso em: 15 Jun. 2020.

PARANÁ (Estado). Tribunal de Justiça do Estado do Paraná. APR - 0003911-82.2011.8.16.0173. Apelante: Reginaldo da Silva. Apelado: Ministério Público do Estado do Paraná. Relator: Desembargador Carvílio da Silveira Filho. 4a C.Criminal. Curitiba, PR, 06 de junho de 2019. Disponível em: https://tjpr.jusbrasil.com.br/jurisprudencia/834741065/pr ocesso-criminal-recursos-apelacao-apl 39118220118160173-pr-00039118220118160173-acordao/inteiro-teor834741072 ?ref=juris-tabs. Acesso em: 15 Jun. 2020.

RIO GRANDE DO SUL (ESTADO). TRIBUNAL DE JUSTIÇA DO RIO GRANDE DO SUL. ACR: 70079449351 - RS. APELANTE: M.P. APELADO:
MINISTÉRIO PÚBLICO DO ESTADO DO RIO GRANDE DO SUL. RELATOR: RINEZ DA TRINDADE. Terceira Câmara Criminal. PORTO ALEGRE, rs, 27 DE junho DE 2019. DISPONÍVEL EM: HTTPS://WWW.TJRS.JUS.BR/BUSCAS/JURISPRUD ENCIA/EXIBE_HTML.PHP. Acesso em: 15 Jun. 2020.

GRECO FILHO, Vicente. Manual de Processo Penal. 11. ed. São Paulo: Saraiva, 2015.

MACHADO, Antônio Alberto. Curso de processo penal. 6. ed. São Paulo: Atlas, 2014.

MALATESTA, Framarino de. Da Lógica das Provas em Matéria Criminal. Campinas: Bookseller, 1986.

MARCÃO, Renato. Curso de processo penal. 4. ed. São Paulo : Saraiva Educação, 2018.

MOSSIN, Heráclito Antônio. Compêndio de processo penal: curso. Barueri, SP: Manole, 2010.

$\mathrm{NUCCl}$, Guilherme de Souza. Curso de direito processual penal. 17. ed. Rio de Janeiro: Forense, 2020. 